\title{
Development of a Vegetable Transplanting Robot
}

\author{
Dong Hyeon Kang ${ }^{1}$, Dong Eok Kim${ }^{1}$, Gong In Lee ${ }^{1}$, You Ho Kim${ }^{1}$, Hye Jin Lee', Young Bong Min \\ ${ }^{1}$ National Academy of Agricultural Science, Rural Development administration, Suwon, Korea, ${ }^{2}$ Dept. of \\ Bio-Industrial Machinery Eng, Gyeongsang National Univ.(Insti. of Agric. \& Life Sci.), Jinju, Korea
}

Received: February $24^{\text {th }}, 2012$; Revised: April 27 $7^{\text {th }}, 2012$; Accepted: May $1^{\text {st }}, 2012$

\section{Abstract}

Purpose: This study was conducted to develop a vegetable transplanting robot which transplants seedlings from a nursery tray to a plant pot using its four fingers. Method: The robot consists of the transplanting part, nursery tray moving part, plant pot moving part, main frame and controller. Two moving parts are controlled by the photo sensor and servo motor. The transplanting part was composed with two components; transporting device using E-MY2H(SMC Corp., Japan) for controlling finger position accurately and finger for transplanting the seedling. Results: Head lettuce using the transplanting robot was transplanted in 21 days after sowing based upon the seed shape measurement and removing examination. The optimal finger shape was thin pin type because it caused minimum damage to the roots of seedlings. Conclusions: The four inclined pin type was applied to remove the seedlings from the nursery tray. In addition, the transplanting capacity of the developed robot was 2800 pots per hour and the rate of success was $99 \%$ and above.

Keywords: Transplant, Finger, Transplanting capacity

\section{Introduction}

Food problems caused by the global warming, climate change, and increasing population have become one of the major issues need to be solved. Under these circumstance plant factory, a developed form of protected cultivation, has gained attention because it can control the light, temperature, and water for improving productivity (Ashida et al, 2007). Plant factory needs technologies such as sowing, seedling, transplanting, cultivating, harvesting, packaging, and shipping, so the automation of these technologies is important to plant factory (Ryu et al, 1997). In plug seeding factory simple process such as seeding, carrying and management of high quality seeds has automated, but the need of automation of the whole process is very demanding because transplanting is still dependent on manpower (Lee et al, 2004; Ryu et al, 1997). The studies on the automation for transplanting plug

\footnotetext{
*Comesponding author: Dong Eok Kim

Tel: +82-31-290-1859; Fax: +82-31-290-1860

E-mail: kde1206@korea.kr
}

seeding in protected cultivation were related to the semiautomation and automation systems. Ryu (2001) developed a transplant system consists of manipulator, end-effector, tray conveyor, and image recognition device and studied the system which end-effector disperse seeding and transplant into the pot. Kim et al (2001) studied transplanting device for pot plants using pneumatic cylinder to grip and convey the plants. Lee et al. (2004) developed a robot hand equipped with planar cam on the upper end of four hand jig. The robot hand was used for the transplanting young seedlings.

The most important thing in developing transplanting robot is that we should decide the optimal method and time through the careful analysis of target vegetable's growing pattern. If the transplanting method is not good, it could yield serious damage to the leaves or roots. Early transplanting make the bed soil off from the plant, late transplanting make the automation difficult due to the abundant leaves.

Therefore, this study examined the target vegetable's growth patterns in order to decide the right time for 
transplanting and developed transplanting robot. In addition, this study investigated the tensile strength force at the moment when the seedling was picked out from the cell tray in order to decide the right method for seedling picking using robot finger. This study also explored the insertion force upon the shape of pin in order to decide the optimal pin shape of robot finger. Lastly, this study examined the efficiency of the developed robot for leafy vegetables.

\section{Material and Method}

\section{Prototype}

Figure 1 shows the schematic diagram and photograph of vegetable transplanting robot developed for this study. The leafy vegetable transplanting robot consists of pot moving conveyor, planting pot moving conveyor, and cell tray moving conveyor. The operating process is as follows. When nursery tray is carried to the bottom part of transplanting pot by conveyor, the sensor signal to stop the conveyor. Four out of twenty plants in the first row in the nursery tray is picked up by the finger and are carried and transplanted to the planting pot. When the transplanting is completed the planting pot is discharged. The distance between the nursery tray and the planting pot is regulated by the distance control cylinder. This device is developed using $200(20 \times 10)$ whole tray. Figure 2 is the operational flowchart for the vegetable transplanting robot. When the nursery plant tray is coming, the robot picks out the seedlings at the 1st, 6th, 11th, and 16th in the first row and transplant to the planting pot. Next, the robot picks out the seedlings at the $2 \mathrm{nd}, 7 \mathrm{th}, 12 \mathrm{th}$, and 17 th in the row and transplant to the planting pot. And it repeats five times to complete the seedlings in the first row and it moves to the next row and redo the process.

Four pick up fingers are moved horizontally to the target seedling, and they are operated to move down to grip the seedling. Since the four fingers are controlled by one cylinder, when the four fingers grip and pick up the seedling, it happens to pick up more than two seedlings around it as in Figure 3. In order to improve the performance the fingers connected to the cylinder are moved down to the top of tray and grip the seedling from the side of it.

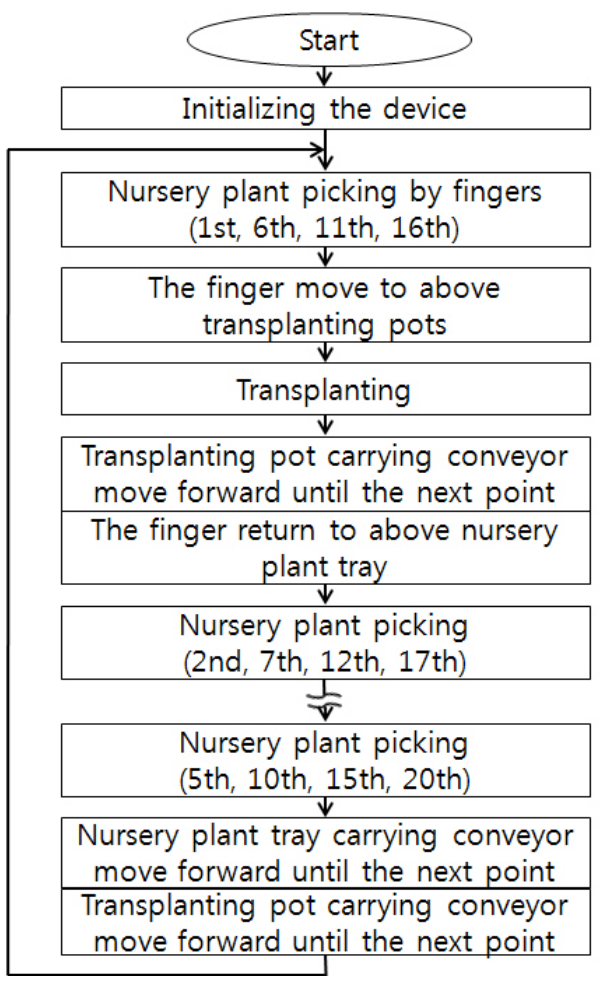

Figure 2. Operational flowchart for vegetable transplanting robot.
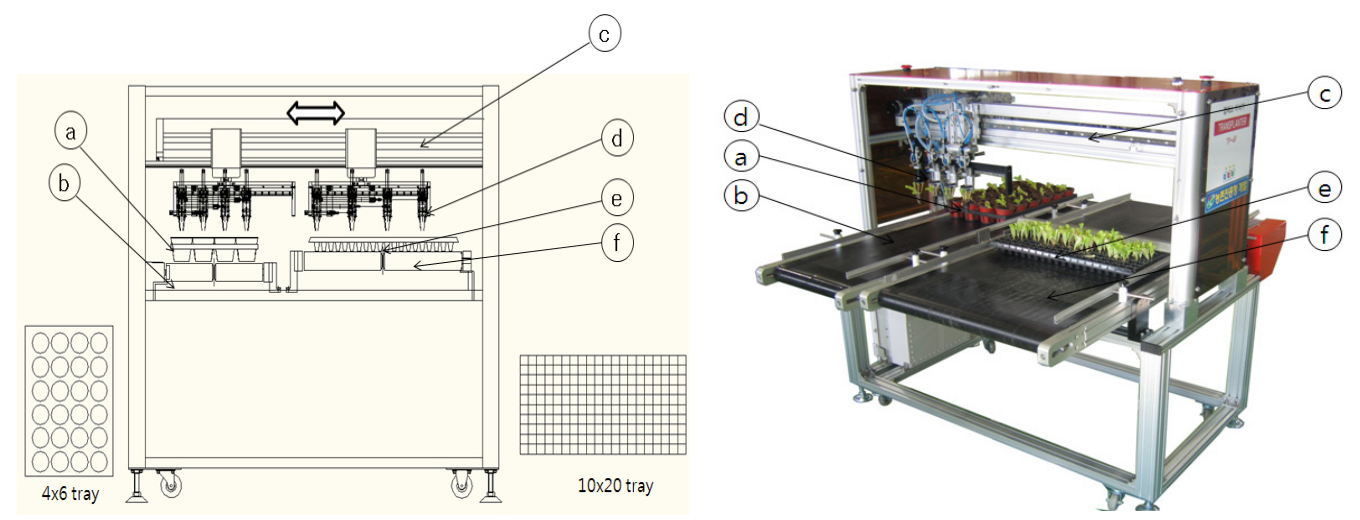

Figure 1. Schematic diagram and photograph of vegetable transplanting robot.

(a) Planting pot (b) Pot moving conveyor (c) Transplanting device (d) Transplanting finger (e) Cell tray (f) Tray moving conveyor 


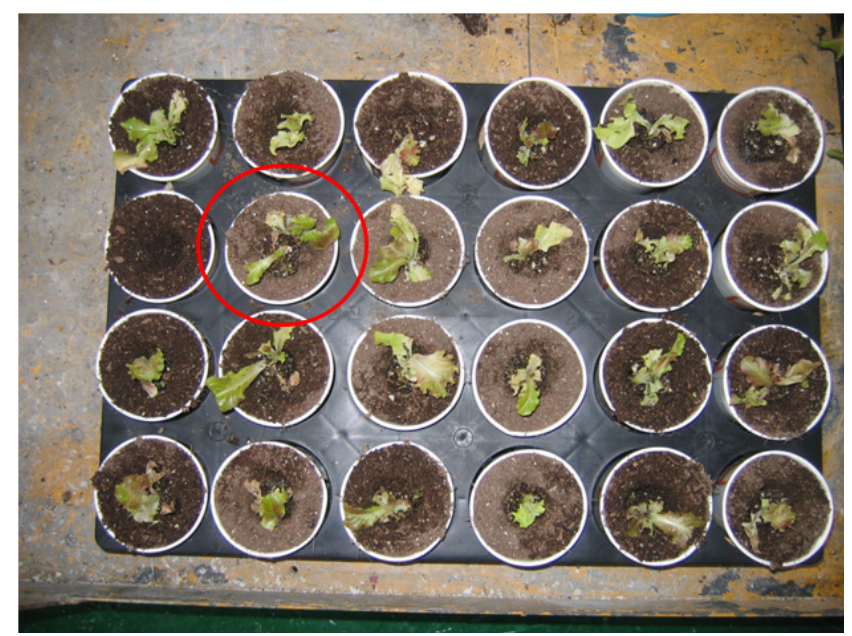

Figure 3. The result of transplanting test.
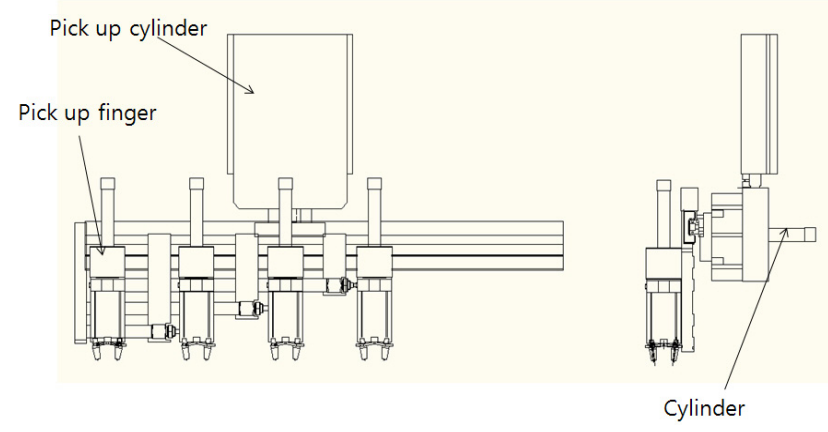

Figure 4. Modification of transplanting finger.

\section{Preliminary experiment}

Sample

This study used head lettuce (Asia lake, Asia seed Co., Korea) for the preliminary experiment to develop leafy vegetable transplanting robot because they can be transplanted and produced by mechanical harvesting. A commercial bed soil (Baroker, Seoul Bio Co., Ltd., Korea) containing cocopeat, peatmoss, and vermiculite was used for the experiment. Bed soil was filled up to the surface of cell tray. Hand sowing was used in the center of each cell of 200 plug cell tray. Seeds were kept for 2 days at the temperature of $21^{\circ} \mathrm{C}$ and $100 \%$ of humidity. After sprouting they were moved to nursery chamber and used for the experiment.

\section{Method}

\section{Seedling experiment}

Growth increment, roots winding, and moisture content of the seedling according to the growth period were investigated in order to decide the pin structure of trans-

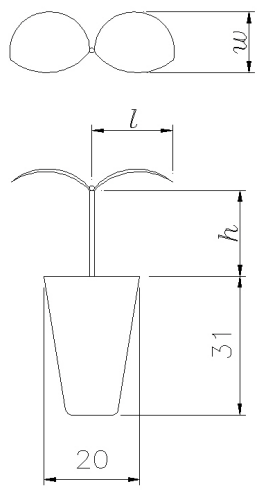

Figure 5. Shape of seedling.

planting robot and workspace. The growth increment of the seedling was examined in terms of the hypocotyls (h) which is the height from the topsoil to a seed leaf, length of leaf (l), and width of leaf (w), and the number of leaves. In addition, fresh weight, dried weight, and moisture content of roots, leaves, and bed soil were examined. Moisture content measurement was followed to the Agricultural Science and Technology Research Investigation Analysis Guideline (Rural Development Administration, 2004 and 2008). According to Good Agricultural Practice Standard Cultivation Guide Book (2008), the best time for transplanting of seedling in nursery tray is $25 \sim 30$ days after sowing, but the time should be decided in relation to the growing of the seedling. The time for transplanting was deicide by observing the degree of roots winding because the roots winding is closely connected to the loss of bed soil which is critical factor in growing.

\section{Removing force estimation}

The process of removing seedlings is the most important part in transplanting by robot. The methods of removing seedlings are follows: a) a pin was used to pick up the bed soil and grip the seedling (Choi et al, 2004a and 2004b; Lee et al, 2004; Ryu et al, 2001),b)a pin push seedlings upward through the draining hole and grip the seedling with bed soil (Min and Moon,1998), and c) gripper grasp the stem of seedling. Those processes cause a separation of the bed soil of seedling from nursery tray. It happens that the seedling come out itself due to the lack of adhesiveness between cell tray and bed soil or lack of roots winding. Thus, calculation of removing force can be used to design a robot and decide the best time for transplanting. In order to get the removing force, measuring apparatus in Figure 6 was used. A stem 
removed leaves was fixed to the apparatus, and the apparatus was connected to property analyzer (TA-HD, Stable Micro Systems Ltd., United Kingdom). 128-holes, 162-holes, and 200-holes cell trays were used to measure and compare the force according to the tray size. When the moisture content of the bed soil is low the removing force decrease. When the moisture content of bed soil is high, the bed soil breaks. For these reasons the measurement was conducted to the seedlings 24 hours after the irrigation, and 18, 21, 24, 27, 30 days after sowing.

\section{Experiment on the Insertion Force}

This study adopted the methods of using a pin to pick up the bed soil and grip the seedling. This method should consider the shape of pin. For this study four shapes of pin which were devised by Ryu et al (2001) and Lee et al. (2004) were used as in Figure 7. Those are 4-Needle type, shove-I type, shove-II type, and Fork type. 4-Needle type has $2 \mathrm{~mm}$ diameter pins and the size is $15 \times 15(\mathrm{WxL}, \mathrm{mm})$. Shove-I type and Shove-II type has stainless steel plates with $2 \mathrm{~mm}$ thickness on both sides. Fork type has rectangle pins and the size is $15 \times 15(\mathrm{WxL}, \mathrm{mm})$. The end of each pin was processed by sharpener and finished with sandpaper. These four types of pin equipped to the property analyzer. The insertion force and the change of bed soil were measured with seedlings grown in 30 days when they pick the bed soil by $20 \mathrm{~mm}$ depth. The measurement repeated ten times.

\section{Gripping the Seedling}

After the pin shape was determined, the method for re-

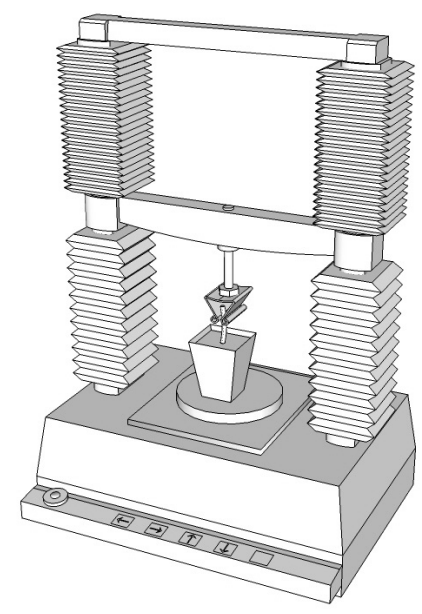

Figure 6. Measuring apparatus of physical properties of seedling. moving seedlings should be needed to minimize the influence on the roots and bed soil. The preliminary experiment on the optimal number of pin revealed that four-pin had the minimum effect to the seedling and bed soil. Thus, four pins were used and three types of removing device were investigated as in Figure 8. First pin type was that four pin was attached to the cylinder as in (a). Hinge in the middle part gripped and removed seedlings vertically. Second pin type was that four pins were attached slanted to the cylinder as in (b). The third type of pin was that the cylinder had four pins and each pin had a guide which had another pin attached slanted to as in (c). The experiment on the success rate of removing and degree of roots deformation were measured by gross. The experiment was repeated 100 times with romaine lettuce grown in 21

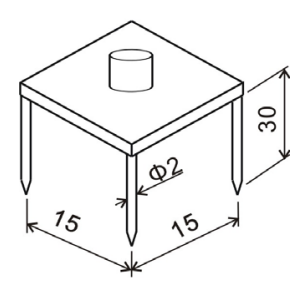

a) 4-Needle type

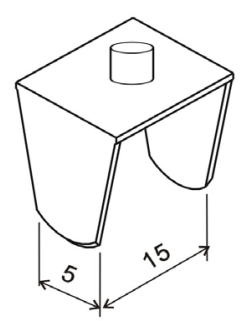

c) Shove-ll type

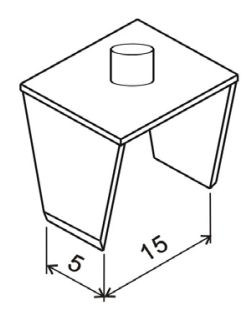

b) Shove-I type

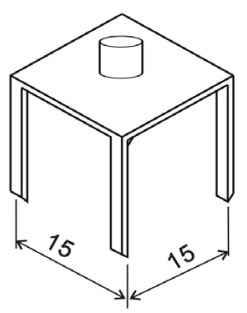

d) Fork type
Figure 7. Shape and dimensions of fingers.

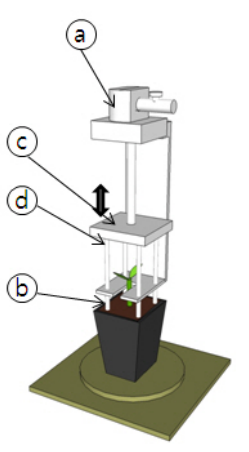

(a) Vertical pin type

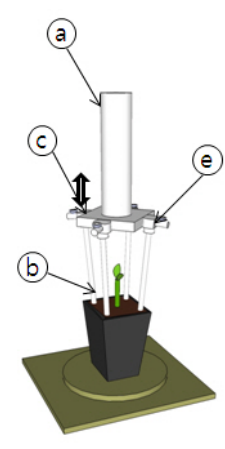

(b) Individual pin type

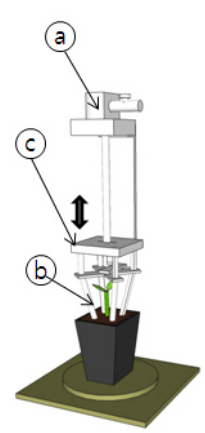

(c) Slope thrust pin type
Figure 8. The take-out device of transplanting robot. (a) Finger operating cylinder (b) Pin (c) Pin frame (d) Hinge (e) Pin operating cylinder 
days.

\section{Performance test}

\section{Conveyor error estimation}

The distance between the cell of 200 hole tray was 25.5 $\mathrm{mm}$ and the size of each cell was $22 \times 22(\mathrm{WxL}, \mathrm{mm})$. It is necessary for gripping the seedling to control precisely. Thus, precision of transport device E-MY2H (SMC Corp., Japan) was measured. Transporting device can be converted within the range of acceleration $0.98-9.80 \mathrm{~m} / \mathrm{s}^{2}$ and controlled within the range of speed $0.01-1 \mathrm{~m} / \mathrm{s}$. Considering the weight of $4.5 \mathrm{~kg}$ of finger part of transporting, acceleration was fixed to $1.96 \mathrm{~m} / \mathrm{s}^{2}$ and speed was controlled to $0.1 \mathrm{~m} / \mathrm{s}$ intervals. And then the error of stop spot was measured. The test was repeated 20 times.

\section{Performance test}

For the performance test of transplanting robot, romaine lettuce which was kept for 21 days after hand sowing at greenhouse in National Academy of Agricultural Science was used as sample. Transplanting process was conducted 24 hours after irrigation. Nursery tray was fed by hand, and pot tray which was punched by device was fed by hand. Two 200-hole nursery trays were used for the test. Success rate and working time were measured. Some empty cells in 200-hole tray were filled with seedling 5 days before the test.

\section{Results and Discussion}

\section{Preliminary test}

\section{Seedling experiment}

Measurement of leaf length, leaf width, and hyopcotyl according to cultivation period were shown in Figure 9.

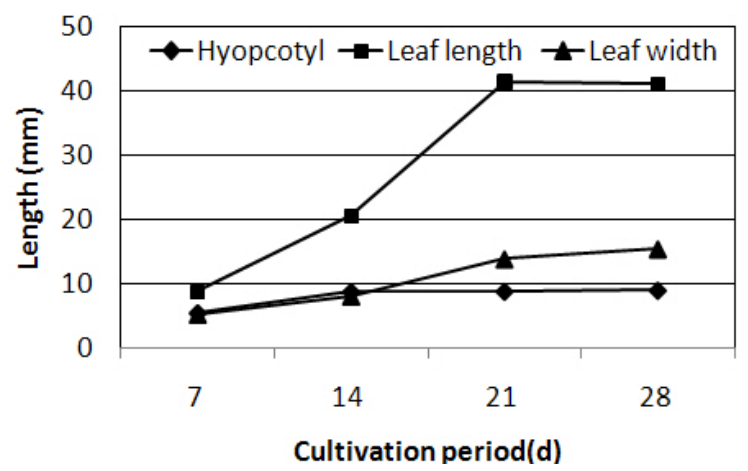

Figure 9. Leaf length $(I)$, leaf width $(w)$ and hyopcotyl $(h)$ according to cultivation period.
Leaf width (w) and leaf length (l) increased as it grew, but 20 days after sowing the size of leaf width kept $40 \mathrm{~mm}$ and leaf length $15 \mathrm{~mm}$. From then, only the number of leaves became increased. Since the size of one cell of cell tray is $22 \times 22$ (LxW, $\mathrm{mm}$ ), the sprouts grew from the cell in two weeks. This factor should be considered in removing the seedling. The size of hyopcotyl (h) was constant in 9 $\mathrm{mm}$ because it was measured in early summer. The change of fresh weight according to cultivation period was shown in Figure 10. The fresh weight became increased until 28 days after sowing and reached over $1 \mathrm{~g}$. Moisture content of leaves is $93 \%$ (W.B.) and roots is $92 \%$ (W.B).

The method which grips the bed soil and removing seedling was closed related to the degree of roots winding for successful transporting. Thus, the experiment on the seedling 10 days after sowing was conducted to decide the right time. Seedling 12 days after sowing can be pulled out with bed soil. However, roots winding was not

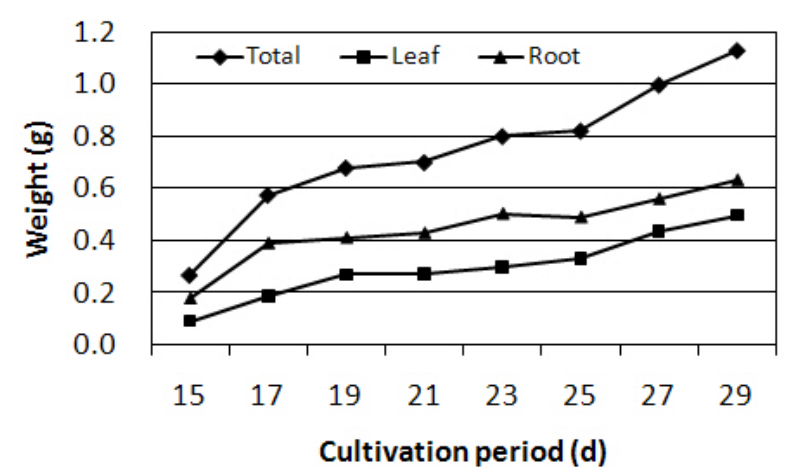

Figure 10. Total, leaf and root weight according to cultivation period.

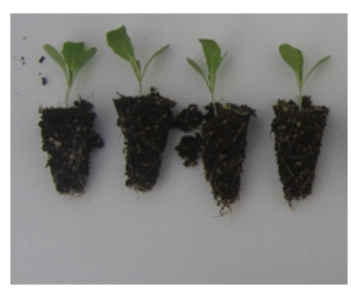

(a) 14 day

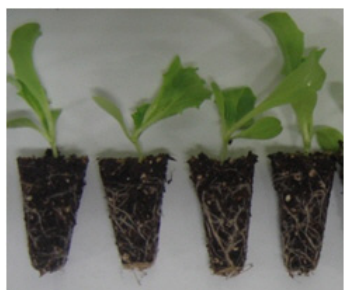

(c) 21 day

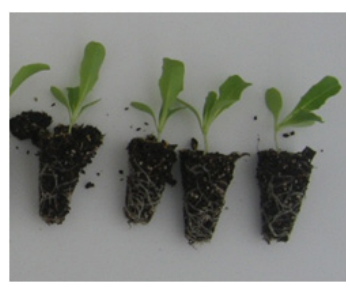

(b) 17 day

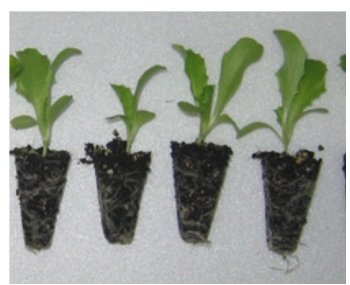

(d) 24 day
Figure 11. Root shapes in nursery box according to cultivation period after seedling. 
enough to hold the bed soil. Figure 11 shows that the seedling and bed soil which removed from the nursery box along with the cultivation period. Roots winding was perfect enough to hold the bed soil in 21 days. For this reason, 21 days after sowing is the best time for transplanting head lettuce.

\section{Removing force estimation}

Measured tensile strength between cultivated seedling and cell tray was shown in Figure 12. Tensile strength of 162- hole and 128-hole cell trays was the biggest in 22 days. Tensile strength of 200-hole cell tray was the biggest in 19 days. This showed that the cultivation period was not main factor to tensile strength.

Optimal time for transplanting is when the tensile strength becomes maximized and when the roots grow to surround the cell. It can be transplanted well without damage to roots. Thus, the best time for mechanical transplanting is that 23 days after sowing in 128-hole and 162-hole tray and 20 days in 200-hole tray.

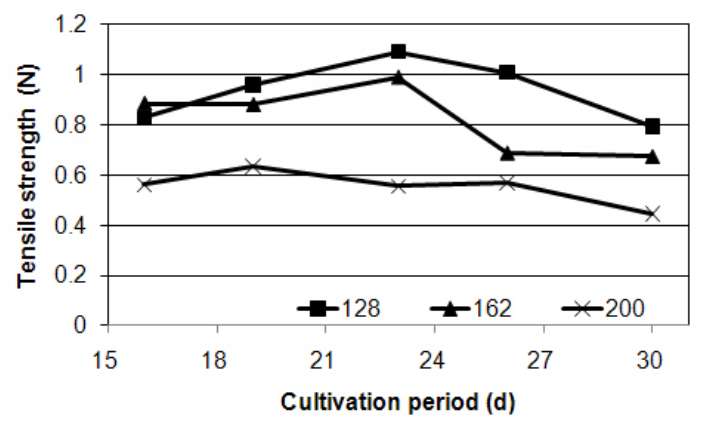

Figure 12. The removing force according to cultivation period.

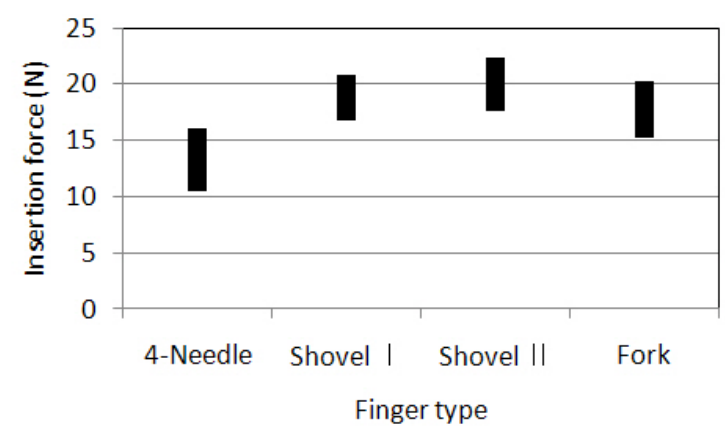

Figure 13. The insertion force according to finger type.

\section{Insertion force of four pin types}

The insertion force of four types of pin was in Figure 13. The insertion force of 4-Needle showed the lowest force with $14 \mathrm{~N}$. Shovel I, II and Fork types had higher force than 4-Needle, but they gripped and took-out the seedling safer than 4-Needle. However, when the finger was inserted into the bed soil, only 4-Needle gripped the seedling without any damage to the soil and roots. For this reason, the 4-Needle was chosen for the finger type.

\section{Gripping the seedling}

Experiment of three kinds of gripping was shown in Ta ble 1 . Vertical moving pin had excellent performance with $100 \%$ success rate, but it broke the bed soil or damaged to leaves and roots. Individual pin had $87 \%$ of successful rate, but it also broke the bed soil due to the difference of each pin's speed. Slope insertion pin showed 100\% success rate in performance with no damage to bed soil or roots, so it was chosen to be the best type for this study.

\section{Performance test}

\section{Conveyor error estimation}

It is not easy to sow the seed exactly in the center of each cell in the nursery tray. Thus, it is necessary to have maximum distance between each pin in order not to damage seedlings. The results of maximum error of the device with moving speed are in Table 2 . The error rate became higher when the moving speed got higher until the speed reached $1 \mathrm{~m} / \mathrm{s}$. Therefore, the distance between pins was designed $20 \mathrm{~mm}$ considering the diameter of pin and safety.

\section{Performance}

Figure 14 shows the operating flow step of the transplanting robot. After finger was dropped as in (a), the seed

\begin{tabular}{|c|c|c|c|}
\hline Items & $\begin{array}{c}\text { Vertical } \\
\text { moving pin }\end{array}$ & $\begin{array}{l}\text { Individual } \\
\text { pin }\end{array}$ & $\begin{array}{c}\text { Slope } \\
\text { insertion pin }\end{array}$ \\
\hline Success rate (\%) & 100 & 87 & 100 \\
\hline Condition of root part & $\triangle$ & $\triangle$ & O \\
\hline
\end{tabular}

Table 2 Maximum error of E-MY2H with moving speed

\begin{tabular}{ccccccccccc} 
Moving speed $(\mathrm{m} / \mathrm{s})$ & 0.1 & 0.2 & 0.3 & 0.4 & 0.5 & 0.6 & 0.7 & 0.8 & 0.9 & 1 \\
Max. error $(\mathrm{mm})$ & 1 & 1 & 1 & 1.2 & 1.3 & 1.2 & 1.4 & 1.4 & 1.5 & 1.5 \\
\hline
\end{tabular}




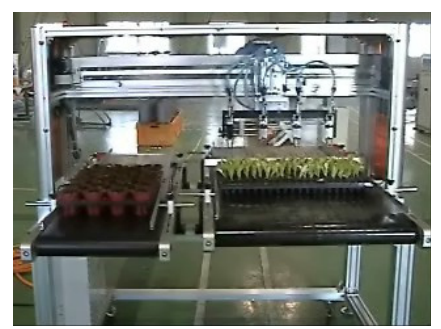

(a) Finger drop

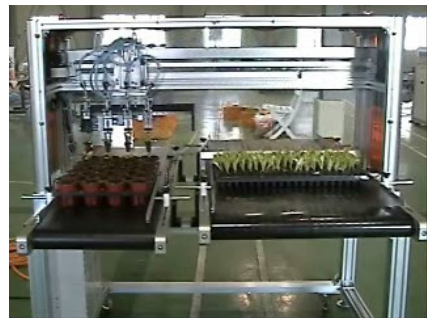

(d) Finger moving

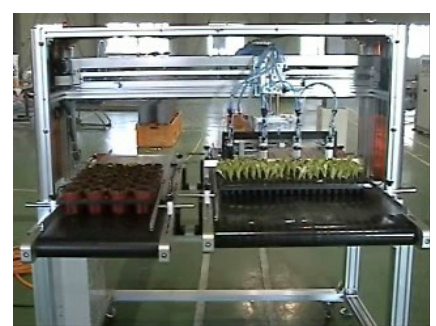

(b) Seed catch

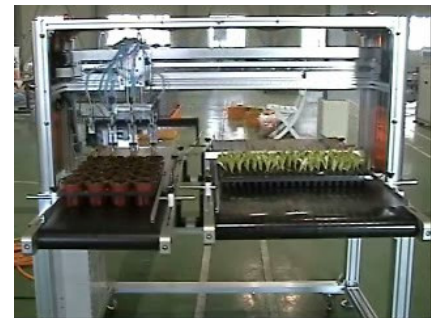

(e) Transplanting

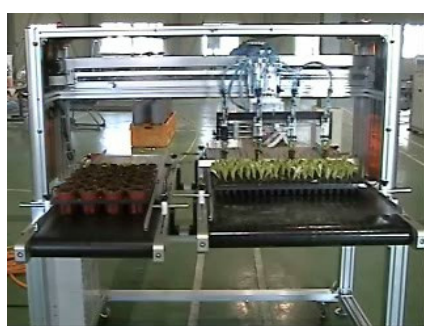

(c) Seed Pick-up

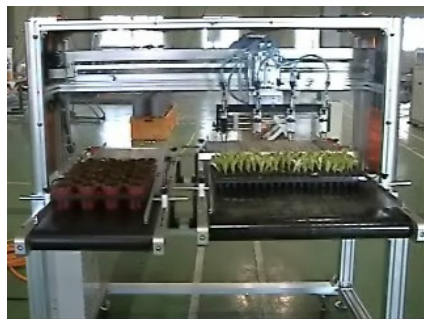

(f) Returns initial point

Figure 14. Operating flow step of the transplanting robot.

was gripped by the pin as in (b). After that, the seedling was removed (c) and moved to over the pot (d) and transplanted (e). (f) shows that the robot return to the initial point. When four seedlings were completed, it would repeat another task. The success rate was over $99 \%$ and 400 seedlings in two nursery tray were transplanted with the speed of 2800 pots per hour.

\section{Summary and Conclusion}

This study investigated the growth pattern and right time for transplanting of head lettuce as a preliminary study for developing transplanting robot. Besides, optimal transplanting pin and transplanting method were examined, and new robot was developed. The performance test also was conducted. The summary of the study is as follows.

(1) Head lettuce grew $40 \mathrm{~mm}$ of leaf width, $15 \mathrm{~mm}$ of leaf length, and $9 \mathrm{~mm}$ of hyopcotyl in 20 days after sowing. The fresh weight became increased until 28 days after sowing and reached over $1 \mathrm{~g}$. Moisture content of bed soil is $72 \%$ (W.B), leaves is $93 \%$ (W.B.), and roots is $92 \%$ (W.B).

(2) Transplanting time was decided based upon the roots winding, and 21 days after sowing is the perfect time for transplanting.

(3) Optimal time for transplanting is when the tensile strength becomes maximized and when the roots grow to surround the cell. It can be transplanted well without damage to roots. Thus, the best time for mechanical transplanting is that 23 days after sowing in 128-hole and 162-hole tray and 20 days in 200-hole tray.

(4) Insertion force test showed that 4-Needle type was the lowest, and slope insertion pin showed no damage to bed soil or roots.

(5) The transplanting capacity of the developed robot was 2800 pots per hour and the rate of success was 99\% and above.

\section{Conflict of Interest}

No potential conflict of interest relevant to this article was reported.

\section{Acknowledgement}

This study was carried out with the support of "Cooperative Research Program for Agricultural Science \& Technology Development (Project No. PJ0065472011)”, Rural Development Administration, Republic of Korea and "Research Program for Agricultural Science \& Technology Development (Project No. PJ0086442012)”, National Academy of Agricultural Science, Rural Development Administration, Republic of Korea. 


\section{References}

Ashida, S., T. Shimizu amd K. Tateyama. 2007. Study of Efficient lighting systems for conditioned greenhouse. Japanese society of agricultural, biological and environmental engineers and scientists 19(2):59-65. (In Japanese)

Choi, W., M. Dohi and N. Ishizuka. 2004a. Development of precision production robot for flover and vegetable seedling (part 1). Journal of Japan Society of Agriculture Machinery 66(2):68-75. (In Japanese)

Choi, W., M. Dohi and N. Ishizuka. 2004b. Development of precision production robot for flover and vegetable seedling (part 2). Journal of Japan Society of Agriculture Machinery 66(2):76-84. (In Japanese)

Kim, S. H., G. I. Lee, D. U. Kim and Y. S. Chang. 2001. Development of automatic transplanter for pot seedling. Proceedings of the KSAM 2001 summer conference 6(2):117-122. (In Korean)

Lee, H. D., K. D. Kim, S. H. Cho and C. S. Kim. 2004. Development of robot hand for transplanting plug seedlings. Journal of Biosystems engineering 29(3):

\section{1-260. (In Korean)}

Min, Y. B. and S. D. Moon. 1998. Automatic feeding and transplanting mechanism for plug seedling transplanter. Journal of the KSAM 23(3):259-270. (In Korean)

Ryu, K. H., G. Y. Kim, H. H. Lee, J. I. Park. 1997. Development of a robotic transplanter for bedding plant( II)Transplanting gripper-. Journal of the KSAM 22(3): 325-332. (In Korean)

Ryu, K. H., G. Y. Kim, H. H. Lee and J. S. Han. 1997. Development of a robotic transplanter for bedding plant (III)- Development of a robotic transplanter-. Proceedings of the KSAM 1997 summer conference 238-246. (In Korean)

Ryu, K. H., G. Y. Kim and J. S. Han. 2001. Development of a robotic transplanter for bedding plant. Journal of agricultural engineering research 78(2):141-146.

Rural Development Administration. 2004. Agriculture science technology research investigation analysis guideline.

Rural Development Administration. 2008. GAP standard cultivation guide book -head lettuce-. 